\title{
Ton \\ IMPROVEMENT OF TRANSIENT STABILITY BY USING FLSTATCOM
}

\author{
Prabha Pandit ${ }^{1}$, Rohit Kumar ${ }^{2}$, Manju Gupta ${ }^{3}$ \\ E-Mail Id: ${ }^{1}$ panditprabha41@gmail.com, ${ }^{2}$ rkkumarr68@gmail.com, ${ }^{3}$ manjugupta@ oriental.ac.in \\ 1,3 Department of Electrical and Electronics Engineering, OIST, Bhopal, India \\ ${ }^{2}$ Department of Electrical and Electronics Engineering, UIT RGPV Bhopal, India
}

\begin{abstract}
Power system stability is one of the most crucial issues which deals with the response of the system to the errors such as: Sudden load change, Short circuit, Prime mover failure, Excitation failure etc. To maintain the stability and the damping oscillation of power system. Recently, FACTS controllers have been proposed to enhance the transient or dynamic stability of the power systems, e.g.: SVC, TCSC, STATCOM. In this a fuzzy logic controller is proposed to apply a suitable control signal to STATCOM. To improve the fault clearing time and transient stability improvement within a particular duration. It is found that the fault clearing times of 0.10sec for generator (G1) under test are self-stable with respect to simulation time. Proposed method is implemented in a single machine infinite bus system and the results are compared with conventional energy function-based controllers.
\end{abstract}

Keywords: STATCOM, Fuzzy Logic Controller, Transient Stability, Synchronous Generator.

\section{INTRODUCTION}

The nonlinear fuzzy controller is proposed to supply a supplementary control signal to STATCOM to increase thecritical clearing time and overcome the uncertainties existing in the power systems. The Proposed method is implemented in a single machine infinite bus system and the results are compared with conventional energy function-based controllers.

Fuzzy logic provides powerful tools to consider these uncertainties and their modelling. To enhance the transient stability of synchronous generator a combination of fuzzy logic controller and STATCOM are employed at generator end. Here the observations clarified that the transient stability on generator terminal was due to LLL-G faults. The main concern is about the positive sequence voltage and active power deviation with and without fault in interconnected power system. The variation in positive sequence voltage and active power is due to LLL-G Fault with respect to time with fuzzy logic based STATCOM(FLSTATCOM) controller. The active and reactive power transfer between the power system and the STATCOM is caused by the voltage difference across this reactance.

As opposed by the modern control theory, fuzzy logic design is not based on the mathematical model of the process. The controller designed using fuzzy logic implements human reasoning that can be programmed into fuzzy logic language (i.e. membership functions and rule).

\section{OBJECTIVES}

The research is to develop the optimization, implementation and methodology, to tune the classical STATCOM controller with Fuzzy logic applied to the alternator terminal.

\subsection{The Main Objective of Purposed Work Includes the following Prospects}

Design a wide area damping control power network, which mainly includes STATCOM based on fuzzy logic (FLSTATCOM) by selecting the proper linguistic variables for the damping of inter area oscillations. In order to compute the stability, the transient stability evaluation is considered.Obtain the controller location for the corresponding alternator location with the chosen input signals. For fulfilling this objective, the normalized values of joint model for controllability and observability indices are determined, according to this the input control signals to the STATCOM are selected.

\subsection{Expected Outcomes of the Research}

The research has been moved out to analyze the Methodology, Algorithm, Optimization and Implementation of STATCOM based on fuzzy logic (FLSTATCOM) and determines the performance of proposed FLSTATCOM.

In the overall research, it is awaited that the proposed wide-area STATCOM based on fuzzy logic (FLSTATCOM) impart much better transient as well as damping performance for the critical inter-area modes of oscillation and guarantees a much superior result comes in terms of fault clearing time, settling time and damping effect as collated to that when conventional STATCOM are employed.Most effective stabilizing signal and control location are achieved for the proposed controller to make the controller more effective.It is expected that the proposed STATCOM based on fuzzy logic (FLSTATCOM) will impart control performance in comparison with the conventional STATCOM. 


\section{J $\mathrm{T}$ - International Journal of Technical Research \& Science}

\section{MATHEMATICAL MODELLING}

\subsection{Modelling of the STATCOM}

The fundamental principle of STATCOM is the generation of a controllable ac voltage source by a VSI connected to a dc capacitor. The ac voltage source appears behind a transformer leakage reactance. The active and reactive power transfer is caused by the voltage difference across this reactance. The ac voltage control is achieved by firing angle control. There are two control objectives in STATCOM control, i.e. ac-bus voltage control and dc voltage control across the capacitor. The modelling and control design are usually carried in the standard synchronous $\mathrm{d}-\mathrm{q}$ frame. The synchronous generator is described by a third-order nonlinear mathematical model. i.e.,

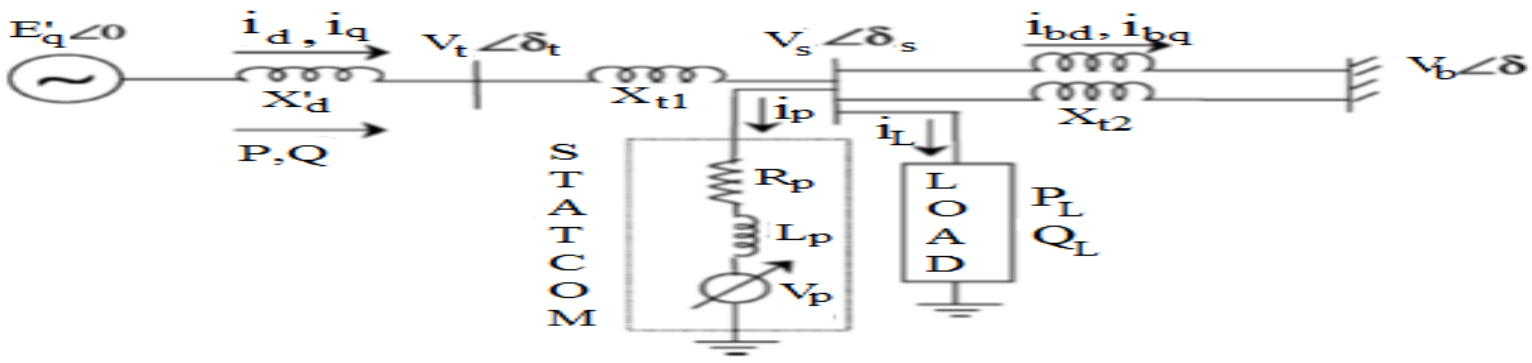

Fig 3.1 Single Machine Infinite Bus Power System with a STATCOM

$\frac{d \delta}{d t}=\Delta \omega$

$\frac{d \Delta \omega}{d t}=\frac{1}{M}\left[P_{m}-E_{q}^{\prime} i_{q}-\left(X_{q}-X_{d}^{\prime}\right) i_{d} i_{q}\right]$

$\frac{d E^{\prime} q}{d t}=\frac{1}{T_{d 0}^{\prime}}\left[E_{f d}-E_{q}^{\prime}-\left(X_{d}-X_{d}^{\prime}\right) i_{d}\right]$

Where; $\Delta \boldsymbol{\delta}=\boldsymbol{\delta}-\boldsymbol{\delta}_{0}$ and $\Delta \boldsymbol{\omega}=\boldsymbol{\omega}-\boldsymbol{\omega}_{0}$

The dynamic equations governing the instantaneous values of the three-phase voltage across the current flowing into it,

$\left(R_{p}+L_{p} \frac{d}{d t}\right) i_{p}=V_{s}-V_{p}$

Where, $\boldsymbol{i}_{p}=\left[\begin{array}{lll}\boldsymbol{i}_{p a} & \boldsymbol{i}_{p b} & \boldsymbol{i}_{p c}\end{array}\right]^{T}$

$V_{s}=\left[\begin{array}{lll}V_{s a} & V_{s b} & V_{s c}\end{array}\right]^{T}$

$V_{P}=\left[\begin{array}{lll}V_{P a} & V_{P b} & V_{P c}\end{array}\right]^{T}$

$\boldsymbol{R}_{P}=\left[\begin{array}{ccc}\boldsymbol{R}_{P} & \mathbf{0} & \mathbf{0} \\ \mathbf{0} & \boldsymbol{R}_{P} & \mathbf{0} \\ \mathbf{0} & \mathbf{0} & \boldsymbol{R}_{P}\end{array}\right]$

$L_{P}=\left[\begin{array}{ccc}L_{P} & 0 & 0 \\ 0 & L_{P} & 0 \\ 0 & 0 & L_{P}\end{array}\right]$

Under the assumption that the system has no zero sequence components, all currents and voltages can be uniquely represented by equivalent space phasors and then transformedinto the synchronous d-q-o frame by applying the following park's Transformation.

$T=\left[\begin{array}{ccc}\cos \theta & \cos \left(\theta-\frac{2 \pi}{3}\right) & \cos \left(\theta+\frac{2 \pi}{3}\right) \\ -\sin \theta & -\sin \left(\theta-\frac{2 \pi}{3}\right) & -\sin \left(\theta+\frac{2 \pi}{3}\right) \\ \frac{1}{\sqrt{2}} & \frac{1}{\sqrt{2}} & \frac{1}{\sqrt{2}}\end{array}\right]$

Where, $\theta=$ angle between $\mathrm{d}$-axis and reference phase axis.

Thus, transformed dynamic equations are

$\frac{d i_{p d}}{d t}=-\frac{R_{p}}{L_{p}} i_{p d}+\omega i_{p d}+\frac{1}{L_{p}}\left(V_{s d}-V_{p d}\right)$

$\frac{d i_{p q}}{d t}=-\omega i_{p q}-\frac{R p}{L_{p}} i_{p d}+\frac{1}{L_{p}}\left(V_{s q}-V_{p q}\right)$

It is to be noted that in the d-axis and q-axis components of the VSI voltage. i.e. Vpd and Vpq, all harmonics, which are near to/above the VSI switching frequency, are neglected. In the real-time implementation of these quantities, they should be converted into modulation index $(\mathrm{m})$ and phase angle $(\varphi)$ :

$\boldsymbol{m}=\frac{\sqrt{V_{p d}^{2}+V_{p d}^{2}}}{K V_{d c}} \quad$ and $\varphi=\tan ^{-1}\left(\frac{V_{p q}}{V_{p d}}\right)$ 
ᄀ T T R S International Journal of Technical Research \& Science

For an effective dc-voltage control, the input power should be equal to the sum of load power (if any) and the charging rate o capacitor voltage on an instantaneous basis. Thus, by power balance between the ac input and the dc output,

$P=\frac{3}{2}\left[V_{s d} i_{p d}+V_{s q} i_{p q}-\left(i_{p d}^{2}+i_{p d}^{2}\right) R_{P}\right.$

$P=C V_{d c} \frac{d V_{d c}}{d t}+\frac{V_{d c}^{2}}{R_{d c}}$

Hence, $\frac{d V_{d c}}{d t}=\frac{3}{2} \frac{V_{s d} i_{p d}+V_{s q} i_{p q}-\left(i_{p d}^{2}+i_{p d}^{2}\right) R_{p}}{C V_{d c}}-\frac{V_{d c}}{C R_{d c}}$

Equation (16) models the dynamic behavior of the dc-side capacitor voltage. In equations (11), (12) and (15) together describe the dynamic model of the STATCOM and is summarized below for readiness in equation (17).

$\frac{d}{d t}\left[\begin{array}{c}i_{p d} \\ i_{p q} \\ V_{d c}\end{array}\right]=\left[\begin{array}{c}-\frac{R_{p}}{L_{p}} i_{p d}+\omega i_{p q} \\ -\frac{R p}{L_{p}} i_{p q}-\omega i_{p d} \\ \frac{3}{2 C V_{d c}}\left[V_{s d} i_{p d}+V_{s q} i_{p q}-\left(i_{p d}^{2}+i_{p q}^{2}\right) R_{p}\right]-\frac{V_{d c}}{C R_{d c}}\end{array}\right]+\left[\begin{array}{cc}\frac{\mathbf{1}}{\boldsymbol{L}_{\boldsymbol{p}}} & \mathbf{0} \\ \mathbf{0} & \frac{\mathbf{1}}{\boldsymbol{L}_{\boldsymbol{p}}} \\ \mathbf{0} & \mathbf{0}\end{array}\right]\left[\begin{array}{cc}\boldsymbol{V}_{\boldsymbol{s d}} & -\boldsymbol{V}_{\boldsymbol{p d}} \\ \boldsymbol{V}_{\boldsymbol{s q}} & -\boldsymbol{V}_{\boldsymbol{p q}}\end{array}\right]$

The performance of the proposed model is tested on two-machines three-bus systems as shown in fig. (1.2).The modelling of a simple $500 \mathrm{KV}$ transmission system containing with two hydraulic power plants (or, Salient pole generator)and Fuzzy Logic based STATCOM Controller are connected at mid-point of transmission line to improve transient stability and power system oscillations damping.

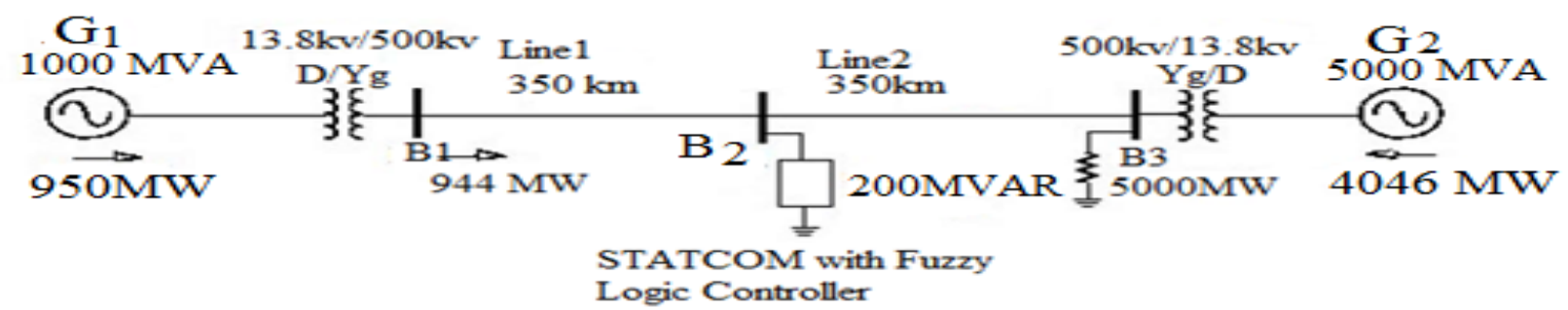

Fig. 3.2 Single Line diagram of 2-Machine 3-Bus system of Power System Model with STATCOM Controller

Table-3.1 System Parameter

\begin{tabular}{|l|l|l|}
\hline Load/STATCOM & Load Power & Bus Location \\
\hline $1^{\text {st }}$ Load & $500 \mathrm{MW}$ & 3 \\
\hline STATCOM & $\begin{array}{l}\text { 100MVA,13.8KV, } \\
\text { 200MVAR }\end{array}$ & 2 \\
\hline
\end{tabular}

Table-3.2 Generator and Transformer Rating

\begin{tabular}{|l|l|l|}
\hline $\begin{array}{l}\text { Generator/ } \\
\text { Transformer }\end{array}$ & Power Generation & Voltage \& Frequency Ratings \\
\hline G1 & $1000 \mathrm{MVA}$ & $16.5 \mathrm{KV}, 50 \mathrm{~Hz}$ \\
\hline G2 & $500 \mathrm{MVA}$ & $18 \mathrm{KV}, 50 \mathrm{~Hz}$ \\
\hline T1 & $1000 \mathrm{MVA}$ & $13.8 \mathrm{KV} / 500 \mathrm{KV}, 50 \mathrm{~Hz}$ \\
\hline T2 & $500 \mathrm{MVA}$ & $13.8 \mathrm{KV} / 500 \mathrm{KV}$, \\
& & $500 \mathrm{~Hz}$ \\
\hline
\end{tabular}

Where; G1 and G2: Generator and B1, B2 and B3; bus no.

A 1000 MVA hydraulic generation plant (G1) is connected to a load center through a long $500 \mathrm{KV}, 700 \mathrm{~km}$ transmission line. A $5000 \mathrm{MW}$ of resistive load is modelled as the load center. The remote $1000 \mathrm{MVA}$ plant and a local generation of 5000 MVA (G2) feed the load. A load flow has been performed on this system with plant G1 generating $950 \mathrm{MW}$ so that plant G2 produces $4046 \mathrm{MW}$. The line carries $944 \mathrm{MW}$ which is close to its surge impedance loading ( $\mathrm{SIL}=977 \mathrm{MW}$ ). To maintain system stability after faults, the transmission line is shunt compensated at its canter by a 200 MVAr, STATCOM. The STATCOM has a power oscillation damping (POD) unit as well as fuzzy logic controller. The other three-phase elements such as the inductive voltage source, the Y grounded/Delta transformer, and the loads are standard blocks from the Electrical Source and Elements libraries of power. If you open the dialog box of the Three-Phase Fault and Three-Phase Breaker blocks, you see how the 


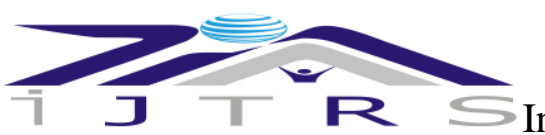

International Journal of Technical Research \& Science

switching times are specified. The Machine Measurement De-mux block provided in the Machines library is used to De-mux the output signals of the Synchronous Machines and Asynchronous Machines. The Synchronous Machine voltage and active power (MW) outputs are used as feedback inputs to a Simulink control system that contains the prime mover and governor block as well as an excitation block. The excitation system is the standard block provided in the Machines library. The Syn. Machine parameters as well as the prime mover and governor models were taken from references. The performance of the proposed system has been studied in a comparative manner. The comparison is performed without considering any FLSTATCOM controller in the system, with conventional STATCOM, with and without LLL-G fault and with LLL-G fault.

\section{FUZZY INTERFACE SYSTEM (FIS)}

The Fuzzy interface method incorporated in this research is using two i/p signals and one output. The input to the fuzzy logic controller is taken as deviation of tie line active power in conjunction with the speed deviation whereas output of controller is a voltage signal. The stabilizing signals are computed using the standard fuzzy membership functions depending upon these variables. The fuzzy inference method is min-max type (Mamdani). The Defuzzification strategy used is the fuzzy 'centroid' method. The membership functions for the two input variables have been chosen identical because of the normalization achieved on the physical variables. FIS editor window is shown in fig. (4.1).

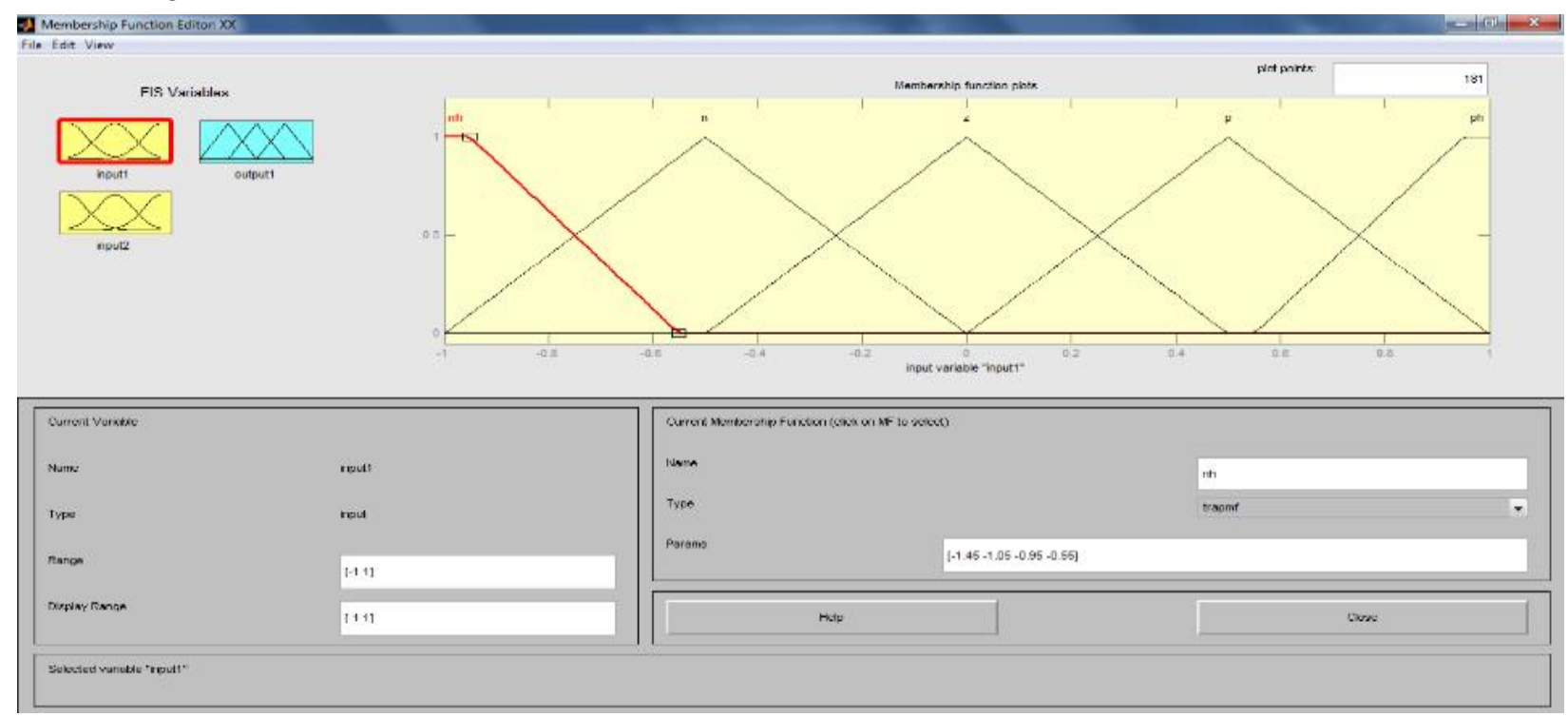

Fig. 4.1 Membership Function Editor for Input-1

The Membership function editor windows for input-2 of fuzzy interface system i.e. v/g signal is shown in fig. (4.1).

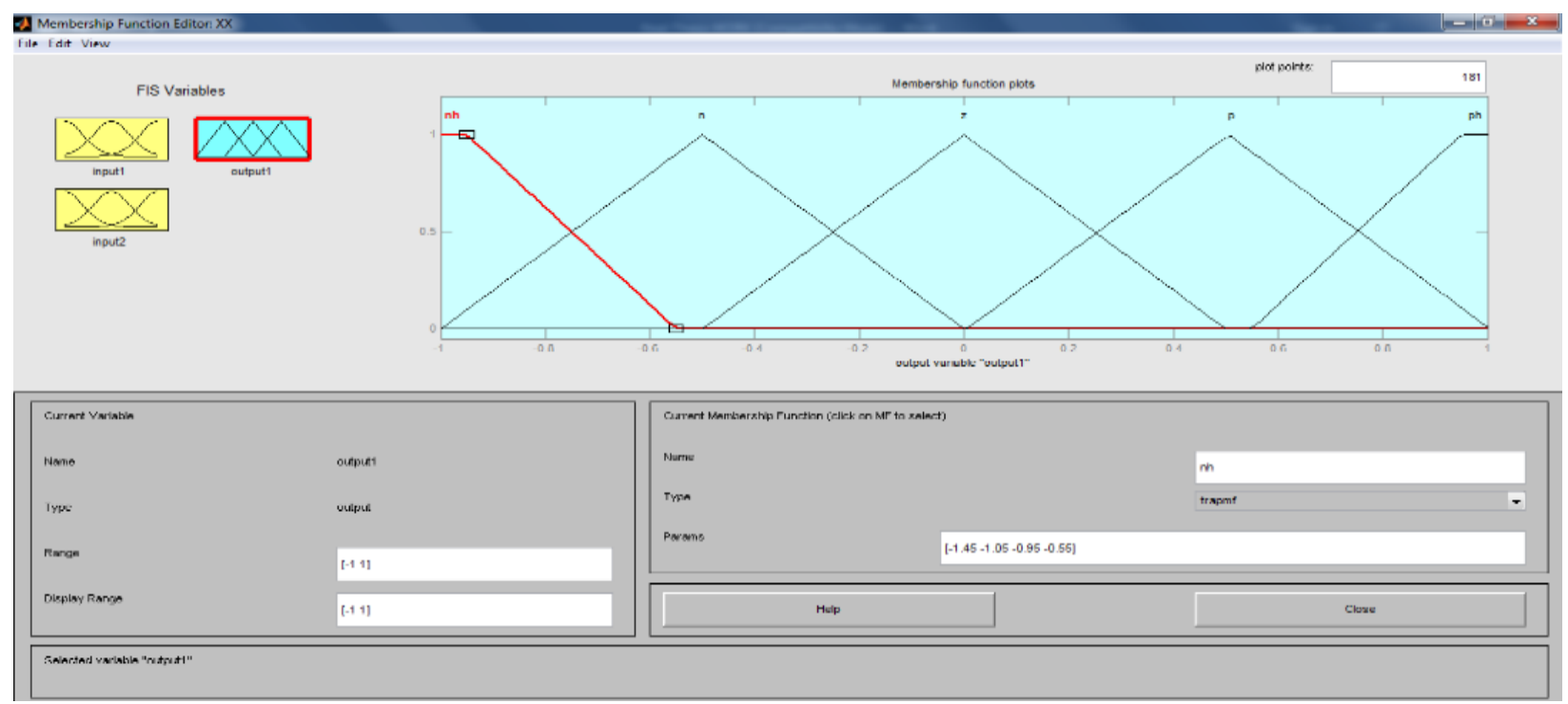

Fig. 4.1 Membership function Editor for output.

The Membership function editor windows for output of fuzzy interface system i.e. v/g signal is shown in fig. (4.2).

DOI Number: https://doi.org/10.30780/IJTRS.V05.I12.005

pg. 15

WWw.ijtrs.com

www.ijtrs.org 
7 ᄀ $\mathrm{T}$ S International Journal of Technical Research \& Science

\subsection{Flow Chart of Implementation}

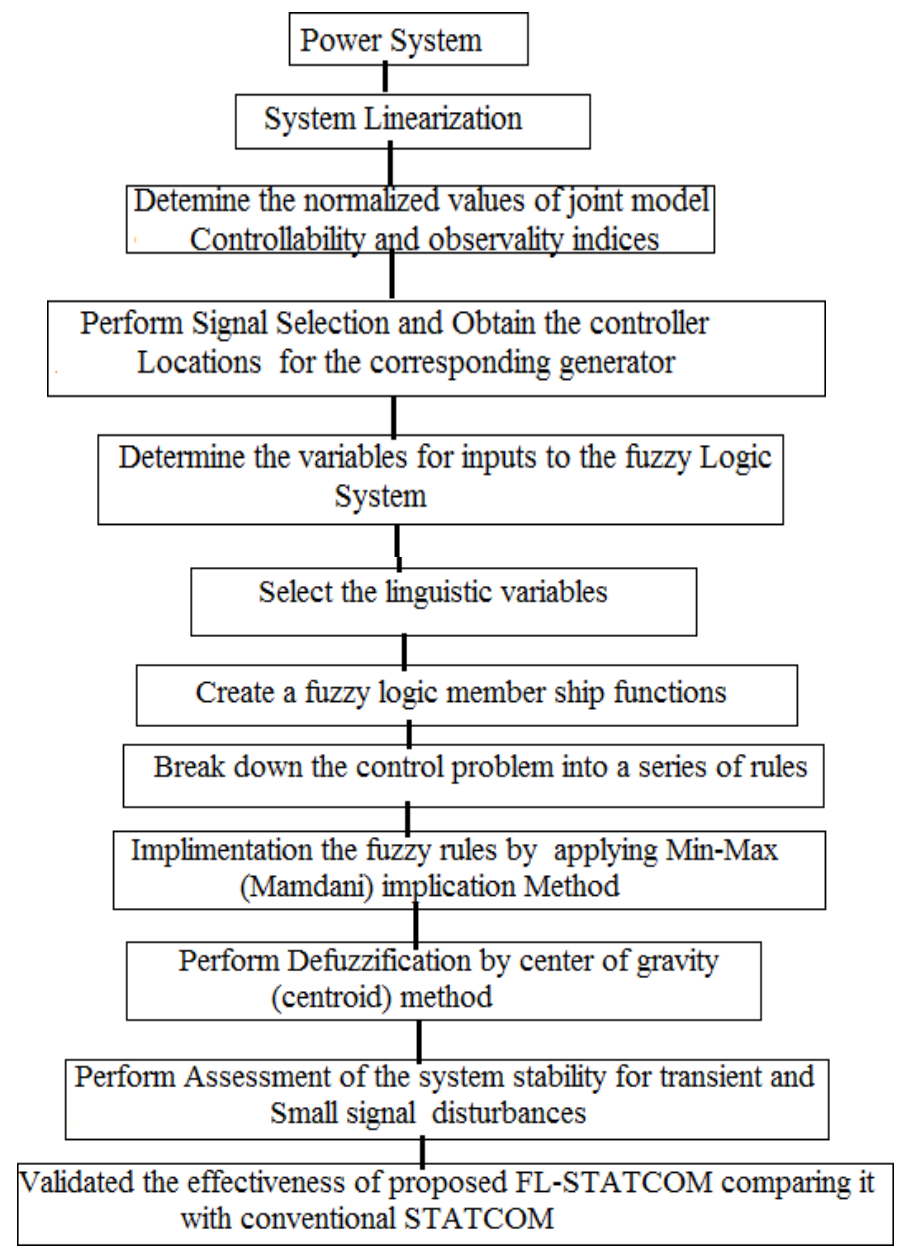

Figure 1.3 Flow Chart for Design process of STATCOM based on fuzzy logic (FLSTATCOM)

\subsection{Rule Base}

The rule base for the fuzzy logic controller is designed. In this research, the choice of 5 membership functions for each of the two inputs has generated 25 rules for each machine. The rule base employing the rules for two inputs i.e. the voltage error and the rate of change of voltage error, ' $\mathrm{e}(\mathrm{k})$ ' and 'de $(\mathrm{k})$ 'respectively recalculated and normalized. The normalized value of ' $\mathrm{e}(\mathrm{k})$ ' and ' $\mathrm{de}(\mathrm{k})$ ' are given to the FLC as inputs. The input and output fuzzy sets are usedboth Triangular and Trapezoidal membership function, which are found to be near optimum. The rule base for the FLC is shown in Table-(1.2), and output is line power, voltage and load angle.

Table-1.2. Rule Base for Proposed FLSTATCOM

\begin{tabular}{|l|l|l|l|l|l|}
\hline $\mathrm{e}(\mathrm{k}) / \mathrm{de}(\mathrm{k})$ & $\mathrm{nh}$ & $\mathrm{n}$ & $\mathrm{z}$ & $\mathrm{p}$ & $\mathrm{ph}$ \\
\hline $\mathrm{Nh}$ & $\mathrm{nh}$ & $\mathrm{nh}$ & $\mathrm{nh}$ & $\mathrm{n}$ & $\mathrm{z}$ \\
\hline $\mathrm{N}$ & $\mathrm{nh}$ & $\mathrm{nh}$ & $\mathrm{n}$ & $\mathrm{z}$ & $\mathrm{p}$ \\
\hline $\mathrm{Z}$ & $\mathrm{nh}$ & $\mathrm{n}$ & $\mathrm{z}$ & $\mathrm{p}$ & $\mathrm{ph}$ \\
\hline $\mathrm{P}$ & $\mathrm{n}$ & $\mathrm{z}$ & $\mathrm{p}$ & $\mathrm{ph}$ & $\mathrm{ph}$ \\
\hline $\mathrm{Ph}$ & $\mathrm{z}$ & $\mathrm{p}$ & $\mathrm{ph}$ & $\mathrm{ph}$ & $\mathrm{ph}$ \\
\hline
\end{tabular}

Where, nh; negative high, $\mathbf{n}$; negative, $\mathbf{z}$; zero, p; positive, ph; positive high.

From Table-1.2, it is clear that each entry represents a particular rule and the stabilized output is obtained by applying a particular rule expressed in the form of membership function. A typical rule has the following structure:

Rule 1: If voltage error, e (k) is nh (negative high) AND change of voltage error de (k) is nh, then the output is nh (negative high).

Rule 2: If voltage error, e (k) is $n$ (negative) AND change of voltage error de (k) is nh, then the output is nh. The fuzzy logic controller model with rule viewer connecting with gain value $(g=-1495)$. 
ᄀ T $\mathbb{R} S$ International Journal of Technical Research \& Science

\section{SIMULINK MODELLING}

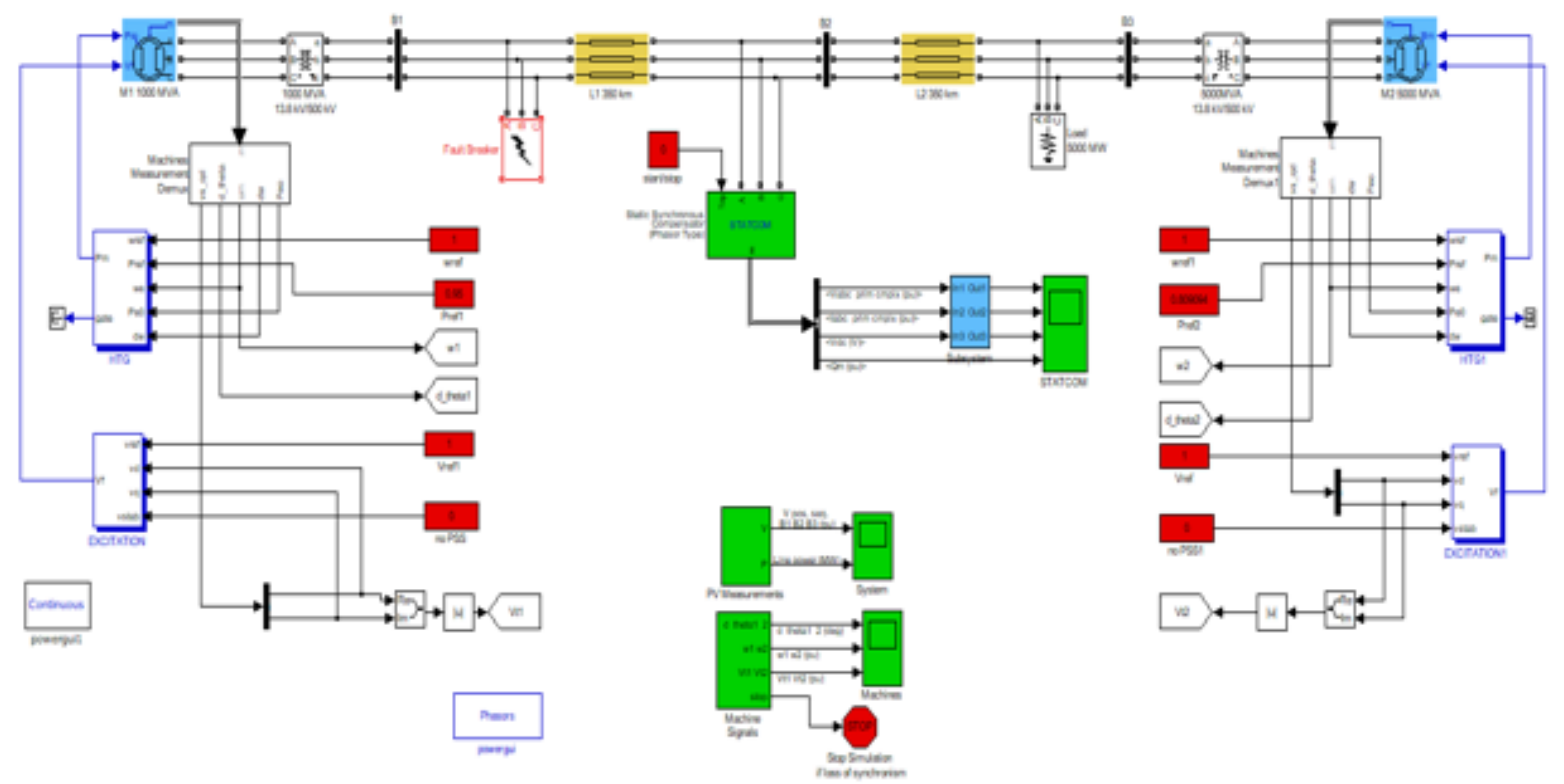

Fig. 5.1 Two-Machine 3-Bus Test System Modelled in Simulink/MATLAB

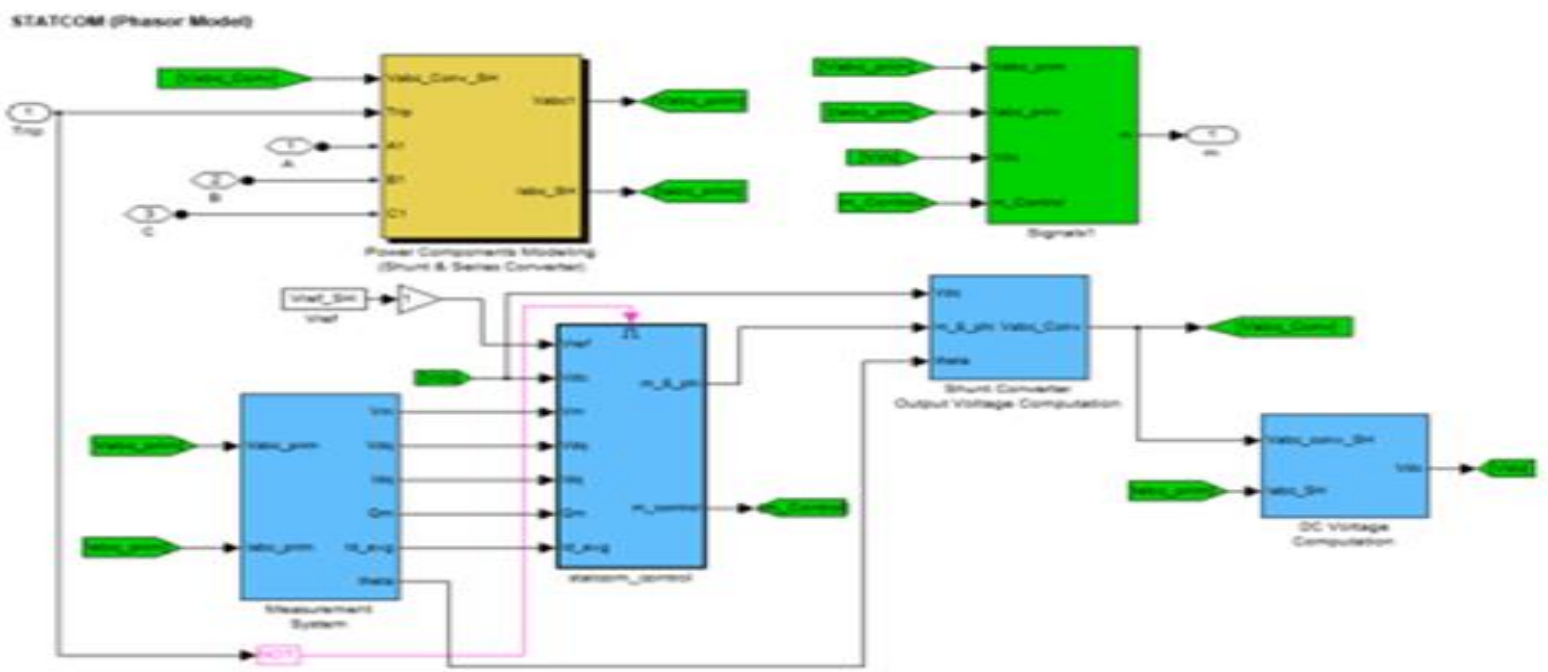

Fig. 5.2 FLSTATCOM Simulink Sub Model Simulink

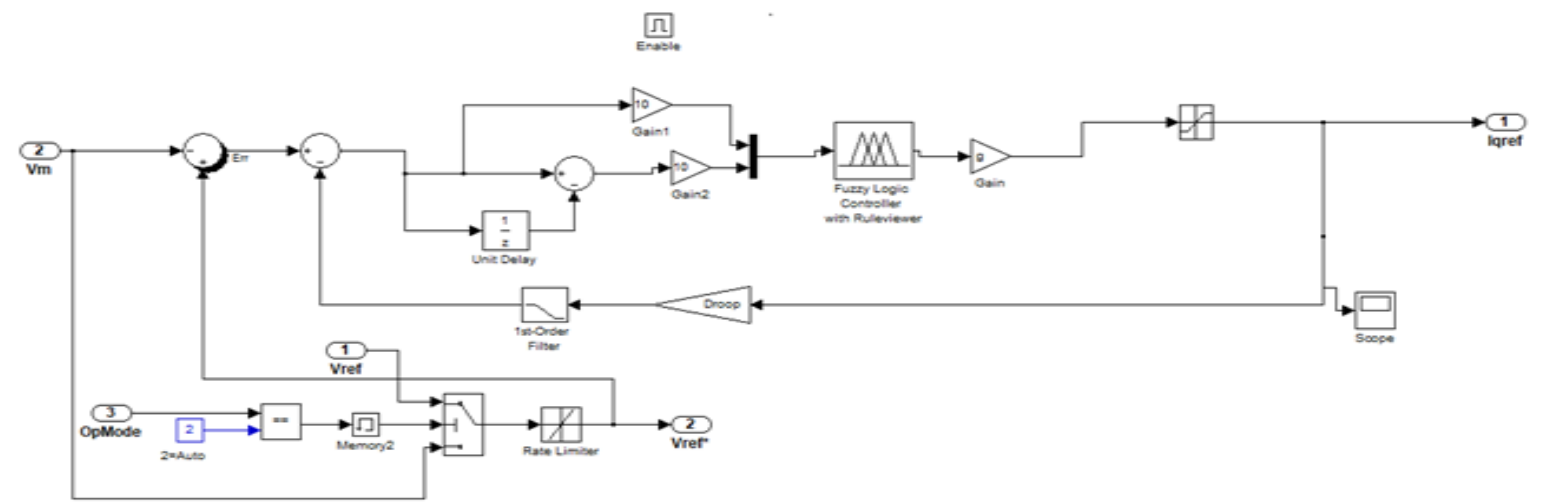

Fig. 5.3 Fuzzy Logic Controller Sub-Model

DOI Number: https://doi.org/10.30780/IJTRS.V05.I12.005

pg. 17 www.ijtrs.com www.ijtrs.org 


\section{7 工 $R$ S International Journal of Technical Research \& Science}

\section{RECORDING OF GRAPHS}

The plots obtained for the assessment of the system stability the large disturbances (transient phenomenon) is present in this section. The parameters considered for the assessment are line active power deviation, generator terminal voltage deviation, bus voltage deviation and rotor angle deviation.

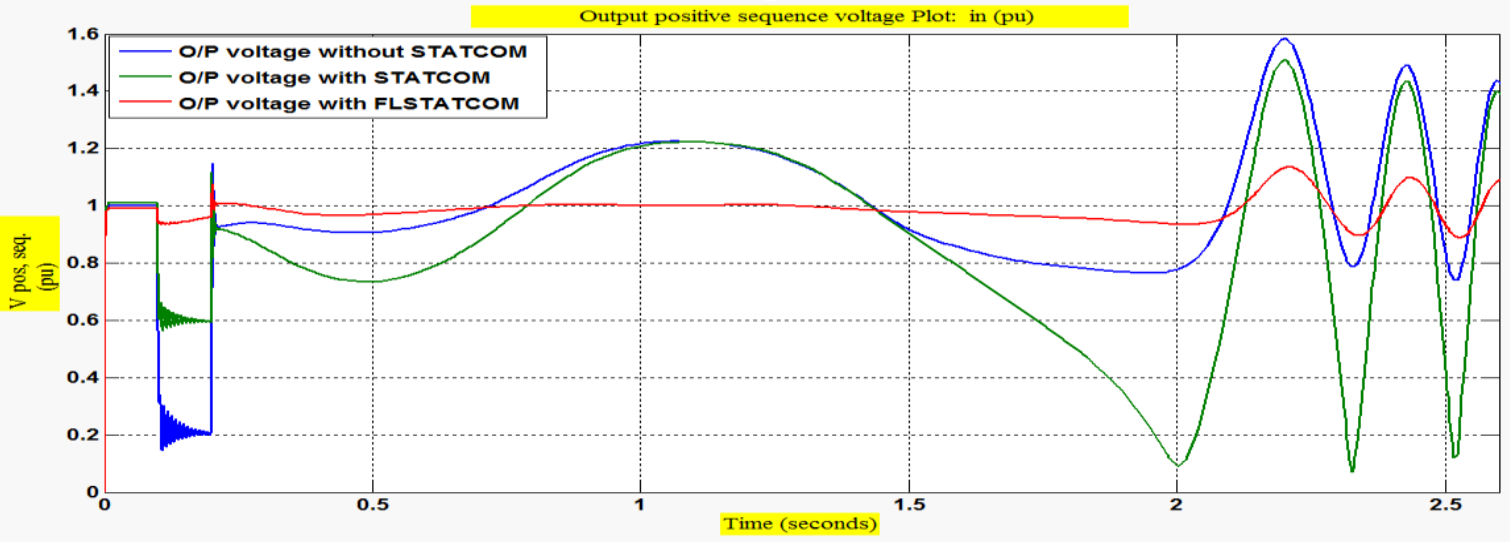

Fig. 6.1 Line Active Output +ve Sequence v/g in (p.u.) with LLLG Fault

The line active power graph is shown in fig. (6.1) with LLL-G fault and within $0.10 \mathrm{sec}$ the fault is clear it-self and regain steady state. i.e. transient phenomenon is die-out within operating regions. The bus line voltages (B1, 2, B3) variation in P.u graphs FLSTATCOM without any fault in the proposed system. The bus line voltages (P.u) variation graphs are shown in fig. (6.2) with FLSTATCOM with LLL-G fault at B1. It is clear seen that within 0.10 second fault is clear it-self. i.e. fault clearing time is $0.10 \mathrm{sec}$.

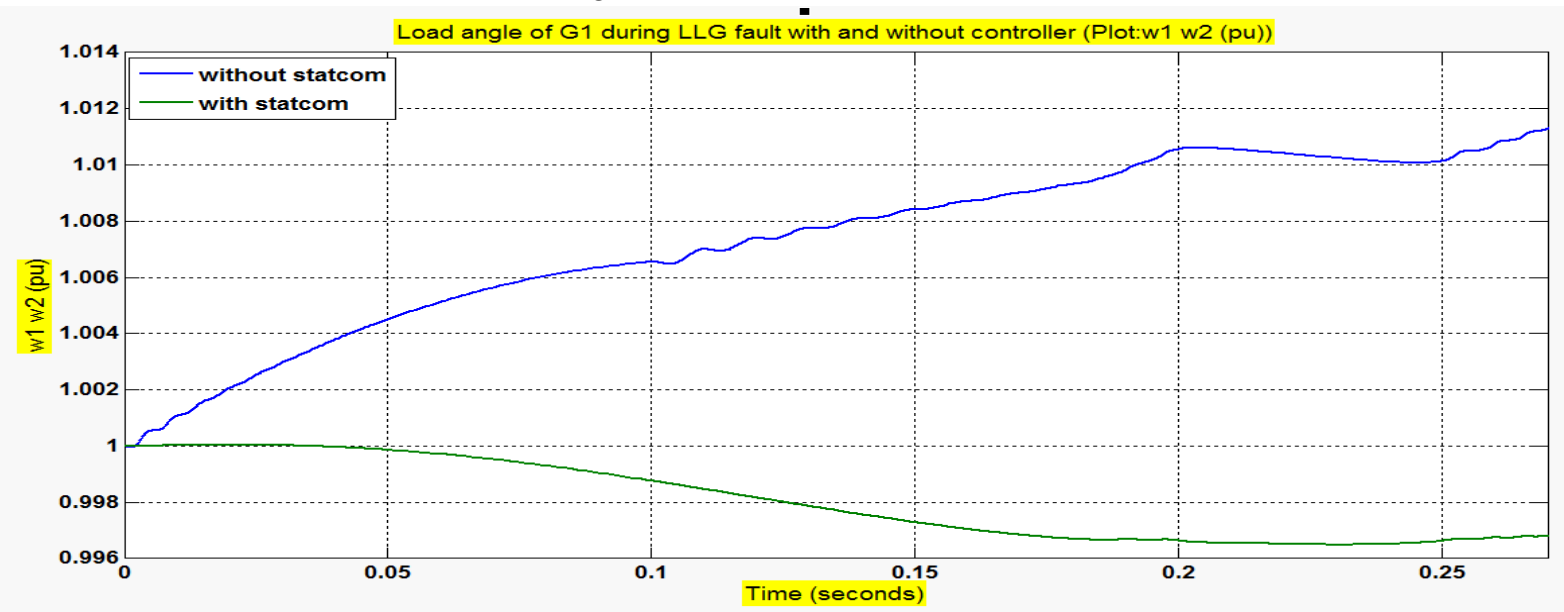

Fig. 6.2 Load angle of G1 during LLG Fault with and without Controller

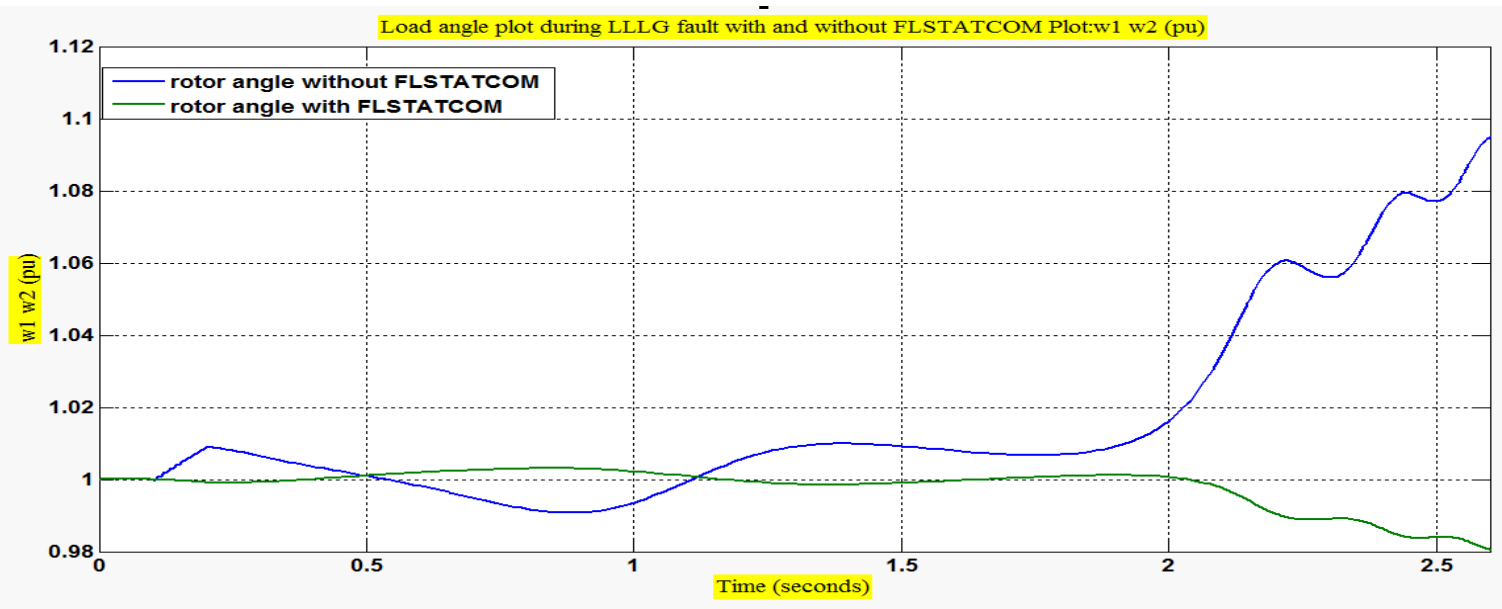

Fig. 6.3 Load Angle of G1 during LLG Fault with and without Controller

DOI Number: https://doi.org/10.30780/IJTRS.V05.I12.005

pg. 18

www.ijtrs.com

www.ijtrs.org

Paper Id: IJTRS-V5-I12-005

Volume V Issue XII, December 2020 


\subsection{Benefits of The Research}

Fuzzy logic has several advantages as collated to conventional controller like- STATCOM, PSS, SVC etc.The following benefits obtained in this research like;

$>$ The methodology is less complicated and faster.

$>$ The designed controller can deal with non-linearity of arbitrary complex closed-loop control problems.

$>$ The research will benefit electrical utility to control the low frequency of interarea oscillations.

$>$ Fuzzy logic is basically based on linguistic variable rule with an IF-THEN structure, which is the basis of human logic due to which it does not require any exact system mathematical model.

$>$ The proposed controller is more rugged than conventional non-linear controllers.

$>$ The proposed controller design is economical and cost effective.

\section{RESULTS ANALYSIS AND DISCUSSION}

The proposed fuzzy logic based STATCOM much better transient as well as damping performance. The research has been carried out to analyze the Methodology, and Implementation of fuzzy logic based STATCOM. Most effective stabilizing signal and control location are achieved to make the controller more effective. FLSTATCOM also guarantees much superior performance as compared to conventional STATCOM, in terms of:

$>$ Fault clearing time,

$>$ Settling time

$>$ Damping effect

The results for transient stability assessment are obtained and the plot for the response of line active power (MW) deviation w.r.t time without any fault and with LLL-G fault are shown. The plot clearly indicates that when the system is operating with FLSTATCOM it effectively enhances the system stability and damps all the system oscillations in order to make the system stable within 0.10 seconds.

It is observed from the results obtained that, with the proposed fuzzy logic-based control scheme, the oscillation of inter area tie line active power, speed deviation of respective generator, deviation of voltage and rotor angle are damped little earlier. Therefore, in this research work, it can be said that the proposed FLSTATCOM performs effectively in transient stability.

\section{CONCLUSIONS AND FUTURE WORK}

\subsection{Conclusions}

It is seen through this paper study that the novel idea which the researcher designed and implement in MATLAB Simulink which can substantially help to improve the performance of fuzzy logic based STATCOM controller and compared in terms of line active power deviation, Voltage deviation and rotor angle deviation is when LLL-G fault occurs in transmission line. This is confirmed by the simulation and implementation of the proposed system. Therefore, it can be concluded that performance of fuzzy logic based STATCOM controller is observed to be better than conventional STATCOM without fault as well as with LLL-G fault. As it shows, the better control performance is in terms of fault clearing time, damping of transient phenomenon and damping effect.

This paper presents the improved behavior of transient stability of a 2 machine 3-bus power system using MATLAB software. As power system is a highly complex system and the system equations are nonlinear as the parameters like-voltage, power, speed of alternator etc. are varying due to load fluctuation, faults, lighting, prime mover failure, excitation failure etc. Due to this the stability of alternators becomes disturbed. Mainly transient stability has more dangerous to existing power system alternator.to overcome and compensate these problems without any time delay the Fuzzy Logic Control based STATCOM connect at appropriate location to enhance the transient stability of the system and improve the dynamic response of the system operating in faulty conditions in a better way and it also effectively enhanced the damping of electromechanical oscillations.

According to non-linear simulation results of a multi-machine power system, it is found that the Fuzzy based Controller work well and is robust to change in parameters of the system and to disturbance acting on the system. A Fuzzy Logic Controller combined with a STATCOM controller mechanism is discussed in proposed work. The idea is to combine the advantages of both the controllers to derive a better performance out of STATCOM.

\subsection{Future Scope}

To reduce the computational complexity of transient stability problems have kept them from being run in real-time to support decision making at the time of a disturbance. If a transient stability program could run in real time or faster than real time, then power system control room operators could be provided with a detailed view of the scope of cascading failure. Faster transient stability simulation implementations may significantly improve the power system reliability which in turn will directly or indirectly affect. The studies in this proposed work for two areas two machine, four bus interconnected power system involve the design, optimization, simulation and implementation of 
ᄀ T $\mathrm{R} S$ International Journal of Technical Research \& Science

fuzzy logic based STATCOM to stabilize the power system network. The following aspects pertaining to future research into the fuzzy logic-based control strategies in the design of STATCOM are suggested:

$>$ The work done in this paper is focused voltage error and the rate of change of voltage error as input variables. The fuzzy logic based STATCOM with frequency as input parameter can be investigated since the frequency is highly sensitive parameter in weak system.

$>$ The design and implementation of fuzzy logic based STATCOM using more complex interconnected power system network can be performed in future.

$>$ Although the optimized fuzzy logic based STATCOM controller has been implemented using MATLAB Simulink and the results are observed to be satisfactory, the methodology needs to be implemented in the actual interconnected power system in the future.

In addition to real time analysis, there are other areas where transient stability analysis could become an integral part of daily power system operations.

$>$ System restoration analysis.

$>$ Economic / environmental dispatch.

$>$ Expansion planning.

\section{REFERENCE}

[1] P. Kundur 1994, "Power system stability and control", McGraw Hill.

[2] Srithorn, Phinit, et al. "Power System Stabilisation Using STATCOM with Supercapacitors." IndustryApplications Society Annual Meeting, 2008. IAS'08. IEEE, 2008.

[3] A Luo "Fuzzy-PI Based Direct Output Voltage Control Strategy for the STATCOM used in Utility distribution system", IEEE Transactions on Industrial Electronics, Vol.56, No. 7, pp 240-24 1, 2009.

[4] M. John Bosco and A. Darwin Jose Raju "Power System Stabilizer Using Fuzzy logic in Multimachine Power Systems"IET-UK International Conference on Information and Communication Technology in Electrical Sciences (ICTES 2007), Dr. M.G.R. University, Chennai, Tamil Nadu, India. Dec. 20-22, 2007. pp. 132-136.

[5] S.A AI-Mawsawi, "Fuzzy Control and Dynamic Performance of STA TCOM", IETECH 1. of Elec. Analysis, 2007, Vol.! No.2, pp. 104-115.

[6] B. Singh, S. S. Murthy, S. Gupta, "STATCOM-based voltage regulator for self-excited induction alternator feeding nonlinear loads," IEEETrans. Industrial Electronics, vol. 53, pp. 1437-1452, Oct. 2006.

[7] M.H. Haque, "Application of energy function to assess the first swing Stability of a power system with an SVC", IEE Proc. Gener. Transm, Distrib. Vol.152, No.6, Nov.2005, pp.806-812.

[8] M.H. Hague, "Improvement of first stability limit by Utilizing full benefit of shunt FACTS devices", IEEE transactions on power systems, vol. 19, no.4, pp. 1894 - 1902. November 2004.

[9] Sedghisigarchi, Kourosh, and Ali Feliachi. "Dynamic and transient analysis of power distribution systems with fuel Cells-part I: fuel-cell dynamic model."Energy Conversion, IEEE Transactions on 19.2 (2004): 423-428.

[10]A. Kazemi and M.V.Sohrforouzani, "Power system damping using Fuzzy controlled FACTS Devices", International conference on Power system Technology, POWERCON 2004, Singapore.

[11] M. M. Farsangi, Y. H. Song, and K. Y. Lee, "Choice of FACTS device Control inputs for damping interarea oscillations", IEEE Trans. on Power Systems, vol. 19, no. 2, pp. 1135-1143, May 2004.

[12] N.C. Sahoo, B.K. Panigrahi, P.K. Dash, G. Panda "Multivariable nonlinear control of STATCOM for alternator stabilization" N.C. Sahoo et al. / Electrical Power and Energy Systems 26 (2004) 37-48 